\title{
SOLIDARIEDADE DESOBEDIENTE: MODOS DE EXISTÊNCIA E OUTRAS SOCIABILIDADES
}

\section{SOLIDARIEDAD DESOBEDIENTE: MODOS DE EXISTENCIA Y OTRAS SOCIABILIDADES}

\author{
Sabrina Batista Andrade ${ }^{1}$
}

\begin{abstract}
Resumo: Esta proposta é um embrião de minha pesquisa de doutorado que deve ser desenvolvida entre o Norte e o Nordeste brasileiro. Visa-se investigar como se engendram ali modos de existência e sociabilidades outras, marcadas pela afetividade e solidariedade, em meio à escassez de recursos considerados tão vitais na atualidade. É também intenção da pesquisa oferecer pistas para uma nomadologia nos saberes e práticas relacionais, acadêmicas e clínicas na procura de sentidos outros para nosso presente político, tendo em vista a possibilidade de pensarmos, agirmos e vivermos de outra maneira, resistindo àquela que se impõe a nós e que hoje se materializa em formas de vida que condicionam nossos afetos e modos de existência.
\end{abstract}

Palavras-chave: Nomadismo; sociabilidade; modos de existência.

Resumen: Esta propuesta es un embrión de mi investigación doctoral que pretende desarrollarse entre el Norte y el Nordeste de Brasil. En ella, busco investigar cómo allí se engendran modos de existencia y otras formas de sociabilidad otras, marcadas por la afectividad y la solidaridad, en medio de la escasez de recursos considerados fundamentales en la sociedad de consumo actual. También es la intención de la investigación ofrecer pistas sobre una nomadología en el conocimiento y las prácticas relacionales, académicas y clínicas, en busca de otros significados para nuestro presente político, considerando la posibilidad de pensar, actuar y vivir de otra manera, resistiéndose a aquella que se nos impone y que hoy se materializa en formas de vida que condicionan nuestros afectos y modos de existencia.

Palablas clave: Nomadismo; sociabilidad; modos de existencia.

Movimento e repouso, velocidade e lentidão, atos que nos corpos constituem seus gradientes diferenciais, seus recursos de não petrificação... Por esta via peguei um voo e fui parar em Belém do Pará. Pela primeira vez no norte do Brasil, a intenção era comer peixe fresco e nadar em praias de água doce, ao mesmo tempo, havia certo colóquio do filósofo francês Gilles Deleuze no meio do caminho. O que não era uma pedra, como diz um poeta brasileiro, mas uma maneira de tornar este deslocamento um trajeto com mais elementos de encontro para uma aventura nada costumeira.

A escolha por esse evento no Norte do país teve o intuito de experimentar outra sociabilidade, um desejo de conhecer "deleuzianos" de outras territorialidades. Coincidentemente, o nome do evento era Variações Deleuzeanas, algo sugestivo para minha primeira deriva amazônica: um jogar-se em território desconhecido, para descobrir, ali, in loco, em meio às relações entre viventes, o que faz a produção acadêmica no eixo Norte-Nordeste de meu país, uma vez que comungamos desta mesma urgência, a de fazer pensar junto com estes tais filósofos vitalistas. Esta era a pista para possíveis acontecimentos.

Pedi hospedagem solidária tão logo foi aceito meu trabalho, e obtive um retorno ligeiro. Fiquei na casa de um dos organizadores do evento, biólogo pesquisador do mestrado na UFPA que,

\footnotetext{
${ }^{1}$ Doutoranda pelo Núcleo de Estudos da Subjetividade da Pontifícia Universidade Católica de São Paulo, sob orientação da Prof. Dra Suely Rolnik. E-mail: sabrina35andrade@gmail.com.
} 
como tantos outros pesquisadores dali e daqui - matemáticos corajosos, educadores inventivos, entre outros -, atuam e escrevem suas pesquisas na vizinhança do pensamento de Deleuze. Este autor, para o biólogo que me hospedou, não era um deus como para mim, o que me causou certo espanto e simpatia imediata. Esta simpatia aumentava à medida que os encontros foram se dando nos três dias em que estive sob os "cuidados" deste rapaz. A princípio fiquei com medo do lugar onde ele morava, perto da universidade, num beco escuro, úmido, ermo. Senti medo. $\mathrm{O}$ fato é que esta paranoia foi se transformando à medida que as primeiras horas em Belém foram passando.

O rapaz sorridente não me perdeu de vista em nenhum momento, oferecendo-me o melhor de seu espaço-tempo, a disponibilidade e atenção de seus afetos. Inclusive não aceitou a ajuda financeira que lhe ofereci por estar partilhando de sua morada. Sua simpatia desbundava singeleza, honestamente. Conjuntamente com esta partilha inominável que ia transformando meu medo em alegria, tecíamos conversas com confiança, bem diretas sobre nossas posições políticas, sobre o evento, e sobre os temas apresentados e propostos, como se nos conhecêssemos há mais tempo que um instante. Fui surpreendida pelas suas questões existenciais desrostificadas, e me vi encabulada com sua demonstração de gratidão e respeito por ter ganhado um pote de doce de leite e uma manteiga de garrafa: ele brincava que faria uma foto com elas. Durante três dias, ali estivemos nós: uma mineira, roceira, que vive na Av. Paulista, em São Paulo, e um paraense de Altamira, região do Xingu, que vive na capital do estado do Pará para estudar, e que carrega consigo uma grande delicadeza. Rimos muito um do outro e, assim, um com o outro.

Parti de Belém, e mais dias se passaram em novos deslocamentos, deslizando sobre embarcações, me embeirando com ribeirinhos, conhecendo e vivendo outras histórias. Vi e ouvi coisas do Norte, simples, diretas e maliciosas, em prosas fáceis e desarmadas, num oferecimento gratuito da graça da existência de cada um, conjugando tão lindamente com aquelas paisagens. Mas por que dizer gratuito? Talvez este gratuito diga dos afetos vitais que não passam pelo juízo de deus, e logo dos homens. Afetos que não barganham ou demandam um tipo de resposta num valor de troca. E a malícia que citei fica a cargo de uma estética da existência fora de uma conduta normativa, que difere de uma sedução vantajosa, muito em voga nos dias atuais, ainda mais em lugares turísticos.

Penso que o Sudeste do Brasil perdeu a mão quando introduziu a subjetividade de colonizado reativo (imobilizado), inferindo ou incutindo ao resto do país um modo de vida segregador, supervalorizando em sua história colonial, através da estratificação de seus recursos naturais e da expropriação capital de corpos, feitos que naturalizam sua subjetividade de colonizado.

O que surpreende e encanta no ribeirinho nortista, e que percebi nesta viagem, foi sua relação com a vida, com o outro, sua percepção destas presenças imanentes. Sua relação com as coisas da terra que não são somente monetarizadas, e nem se amparam na confecção ou sustentação de uma imagética prêt-à-porter nos seus modos de existência. Talvez eu esteja falando que as relações ali estejam mais próximas de uma ancestralidade não ocidentalizada, que abarca amplificadamente seu "meio associado", seu campo de forças vivas. Estando ali estas forças de si, extrapessoais, mais intocadas e preservadas do que a dos povos do Sul do país.

Volto para São Paulo num looping de meus horizontes e atmosferas. Germens estão a borbulhar e pedem passagem em novos atos.

Eis então o que seria necessário fazer: instalar-se sobre um estrato, experimentar as oportunidades que ele nos oferece, buscar ai um lugar favorável, eventuais movimentos de desterritorialização, linhas de fuga possíveis, vivenciá-las, assegurar aqui e ali conjunções de fluxos, experimentar segmento por segmento dos contínuos de intensidades, ter sempre um pequeno pedaço de uma nova terra (DELEUZE; GUATTARI, 1997a, p. 24). 
Nos textos finais de meu mestrado, trouxe a ideia de uma solidariedade desobediente, e não pude compreendê-la devidamente naquele momento. Esta ideia, como campo multiplicitário, continua tilintando como pergunta insurgente, viva e aberta para ser experimentada. Esta questão da solidariedade desobediente retornou durante minha estadia em Belém do Pará, em novembro de 2018, ainda no rescaldo da eleição para presidente da República de meu país. O impacto da diferença de atmosfera entre regiões me causou alívio, mas também trouxe a urgência de levantarmos alguma perplexidade pela diferença de nossas formas de ver a vida e concebermos seus sentidos.

Sentidos são invenções que se ramificam na trama social, e podem ser transformados na modulação de nossos desejos. Esta velha questão da produção desejante torna-se ainda mais urgente quando percebemos a força de cristalização das formas de vida servindo tão voluntariamente aos aparelhos de captura. Vemos o desejo perdendo, assim, sua potência vital, sua força pulsional, prépessoal, aquilo que pode constituir um $\mathrm{CsO}$ coletivo, nosso tecido mais singular de criação da realidade. Nesse caso, é muito prudente que sentidos mortificados sofram um processo que chamamos de transducção, isto é, que difiram seus códigos. É muito prudente produzir encontros que desviem os afetos que nos levam a ver a vida como um produto acabado pela força de antigos condicionamentos. É neste viés que esta proposta busca uma espécie de solidariedade desobediente.

Corpos desobedientes àquilo que parece naturalizado e comum na produção de nossos afetos e valores no contemporâneo, contrários molecularmente àquilo que não funciona e que só nos mortifica. Uma solidariedade num viés errático em relação a uma suposta via de conduta, um perder(-se) cartograficamente, para, quem sabe, sejam descobertas novas nuances do existir, do estar junto, e, porque não, de experimentar outros corpos diferentemente daquilo que denominamos "empreendedorismo de si" - nódulo duro dos processos de produção de subjetividades de nossa época, onde se atua apenas para si ou por dinheiro. Sendo assim, como sustentar o que há nas relações para além destas barganhas de interesse, tão comuns entre muitos de nós? Esta difícil sustentação contribui para uma escuta outra, para nos deixarmos afetar pelo que acontece a partir de encontros que não conhecemos, para que possamos, eventualmente, descobrir ou inventar aquilo que não sabemos sobre nós e nossos corpos e afetos.

Desfazer o organismo nunca foi matar-se, mas abrir o corpo a conexões que supõe todo um agenciamento, circuitos, conjunções, superposições e limiares, passagens e distribuições de intensidade, territórios e desterritorializações medidas à maneira de um agrimensor. No limite, desfazer um organismo não é mais difícil do que desfazer outros estratos, significância ou subjetivação. (DELEUZE; GUATTARI 1997a, p. 22)

No Brasil, no final de 2018, muitos de nós, analistas e terapeutas, perdemos a mão em nossos consultórios durante o processo eleitoral. E estivemos colados ao sentimento de impotência e perplexidade com os matizes com os quais a realidade se apresentava então. Não poucas vezes, pudemos contar com a solidariedade de nossos próprios pacientes no atravessamento daquele momento difícil de digerir - mais uma pista para pensar a "solidariedade desobediente". A questão é que a circunscrição dos lugares tipificados se desorganizou um pouco na urgência da assistência mútua necessária naquele momento. Uma espécie de destituição de lugares e papéis sociais que nos fazem assistir juntos a ruína de um tempo histórico. Considerando que, não raramente, nós cuidadores nos esforçamos para carregar um pouco de naturalidade e distanciamento no atravessamento de certos ocorridos clínicos, penso que esta emergência é desobediente ao status $q u o$, mas carrega consigo algo de mais valioso e que não passa pelo valor da sessão, mas pelos vínculos vitais constituídos em nossas relações. Nesse momento, diferentemente do que esperávamos, pudemos experimentar juntos nossa precariedade, nossas zonas de ruína, que se 
encontravam em contemplação mútua através de um triste e difícil processo de desubjetivação coletiva, na morte processual daquilo que acreditávamos incorruptível em nossas existências. É preciso não esquecer, como nos lembra Deleuze, que "Toda forma é precária, pois depende das relações de forças e de suas mutações." (DELEUZE, 2005, p. 139).

Um dos efeitos da viagem ao Pará, na sequência destes acontecimentos clínicos e políticos, foi uma espécie de despertar emergencial para um desejo de compor com as bordas, criar lógicas a partir de afetos despertos e seus efeitos, isto é, ampliar a conversa com o diagrama de forças que tecem nossos encontros nesta Terra, numa amplitude de escuta com o corpo que perceba a si e ao entorno conjuntamente, na busca de novos universos de referência, que difiram também das formas que aprendemos a militar e a fazer política como esquerda. Não se trata de fazer apenas uma crítica, mas de incluir sobretudo o que tangencia uma micropolítica dos afetos nos movimentos de esquerda, uma vez que estes, condicionados à subjetivação de nosso tempo histórico, também "perderam a mão" em suas condutas e nos aspectos afetivos, estes que dizem respeito a como e por onde se conduz uma experiência com o outro que possa passar pela apreensão da alteridade em si. Isso seria dizer, sem rodeios, que "perder a mão" é também perder os sentidos de nossas lutas, perder as palavras que as nomeiam, perder os afetos que as ativam, e as ferramentas que vínhamos usando até então.

Se a maioria é ninguém e a minoria é todo mundo, como nos aponta Deleuze, a conquista de uma estabilidade emocional e financeira é uma falsa ideia que nos é vendida a um alto custo: o enrijecimento de nossos corpos e afetos no abuso de nossas forças vitais. Essa lógica do abuso busca, na justificativa de uma luta pela vida, sobrepor-se a outras vidas, hiperqualificando a individualidade humana - esta que é corrosiva aos potentes encontros, os quais também o humano produz com outros corpos. Um corpo desobediente a esta falsa ideia de estabilidade está para o improvável, produzindo linhas de fuga ao adoecimento do corpo social, tornandose menos apto a padecer de estratos fascistas e a projetá-los nos outros em forma de juízo e ressentimento. O hábito humano gira em torno de um centro de conhecimento que nos conduziu ao que somos hoje, que modula o desejo complexamente, focalizando o ente humano, com seu privilégio neocortical, acima da cadeia dos animais viventes e de toda a vida planetária.

Sujeitos neoliberais que somos, nesta idade geológica da Terra, teremos ainda tempo de nos organizarmos desde onde estamos, de como somos agora, para produzirmos um quantum diferencial de contágio que modifique os saberes que temos sobre nós mesmos e também a nossa experiência coletiva? A tarefa é grande, porém minoritária, pois "se abordarmos os regimes totalitários não em sua face visível, macropolítica, mas sim em sua face invisível, micropolítica, constataremos que o que caracteriza tais regimes é o enrijecimento patológico do princípio identitário"2.

Em tempos de empreendedorismo autoimposto e competitividade naturalizada, vividos como formas de produção das subjetividades, vive-se na experimentação constante de uma escassez imaginária dos recursos mais vitais que temos disponíveis para nos produzirmos. $\mathrm{O}$ contrário desta alienação que parece autoimposta e imperceptível para alguns, é o que tento chamar de solidariedade desobediente. Desobediente à cartografia cultural vigente, esta solidariedade atenta para uma vitalidade da qual nós, humanos, estamos sendo despossuídos. Trata-se da possibilidade de sermos gentilmente cooperativos, simpaticamente abertos ao que difira de nós mesmos e de nossos planos. Praticando uma solidariedade desobediente, ativamos um plano de composição para os múltiplos desejos que compõem a malha social, o que toca também o pressuposto básico para a constituição de uma clínica, ou de clínicas, como espaços e temporalidades que trabalhem para a propulsão de vida, de liga, de outros contágios entre os

\footnotetext{
${ }^{2}$ Disponível em: http://www.pucsp.br/nucleodesubjetividade/Textos/SUELY/Geopolitica.pdf. Acesso em: 6 maio 2016.
} 
vivos. Uma performatização da pulsão que, fora da representação de um mundo caduco, ultrapasse os próprios poros e da vida individualizada. E que pode parecer uma experimentação inusitada, pois libera certas cadeias do pensamento, não como num abalo sísmico, mas como uma elaboração gradual que irrompe linhas duras.

A sustentação mútua de uma desestabilização de corpos condicionados historicamente, que os infira a outras percepções, carece de acompanhamento, escuta e cuidado, para assim produzir alguma diferença no campo da clínica. Todavia, tais experimentações e trocas correm o risco de enclausurarem-se na experiência das subjetividades coloniais, nas belas palavras sem lastro, nas bolhas confortáveis que criamos. É desejável resistir às artimanhas de um modo de conduta que privilegia as práticas privativas, mantenedoras do medo e do alheamento nas condutas sociais. Como sabemos, velhas máquinas de controle estão agora cooptadas por novas tecnologias de captura e modulação desejante.

Deleuze relembra Foucault após sua morte, e fala de seus conceitos, saberes e poderes, como relações entre formas e forças, respectivamente. Os saberes seriam as formas que vão se cristalizando ao longo da história de nossos processos de subjetivação. Os poderes os diagramas de forças que estão sempre submetidos a um Fora absoluto, e que contém a potência mesma de modificar a estratificação dos saberes constituídos. Conhecer as forças sem temê-las, sem julgálas, apenas sendo com elas a incorporação imediata de seus apelos a um corpo que pode estar despotencializado e esquecido, testá-las, atravessar com elas uma experienciação, é um risco a se correr. Mesmo que para isso, ou melhor, ainda que com isso, se precise compor com outros corpos de outras forças. Não precisamos estar sós nesta empreitada, seja na medida de alguma espécie de auxílio clínico, na ocorrência de um levante insurgente de nossos corpos coletivos, ou apenas na composição de uma contradança pela biosfera terrestre.

Todo dispositivo se define, assim, por seu teor de novidade e criação de mundos, que ao mesmo tempo marca sua capacidade de transformar-se, ou de fissurar-se já em proveito de um dispositivo do porvir; a menos que, pelo contrário, haja um abatimento de força sobre suas linhas mais duras, as mais rígidas ou sólidas. Enquanto escapam das dimensões de saber e de poder, as linhas de subjetivação parecem particularmente capazes de traçar caminhos de criação, que não param de abortar, mas também de ser retomados, modificados, até a ruptura do antigo dispositivo.

Diante do que temos como horizonte em nossas formas de vida atuais, o que esta pesquisa quer é "perder a mão", produzir o absurdo contra o abuso de nossas forças vitais. A clínica, seja ela entre duas pessoas ou mais pessoas, é atravessada por este turbilhão vitalício dos diagramas de forças. Assim como as festas bem vividas, as experimentações presentificadas em seus atos, os encontros inusitados que podemos ter nas filas, nos pontos de ônibus, e na criação de outros tantos intensivos processos, engates possíveis sem os quais a vida torna-se um tédio, mero trajeto ou uma função normativa. As forças nômades são as potências mesmas a penetrar em nosso corpo-matéria estratificado, incorporais que nos convocam à vida, mesmo que sejam aparentemente estranhas e incomuns, pois não nos oferecem respostas prontas, apenas movimento.

Anestesiados pela ideia de uma realidade pré-concebida, transferimos a ela a produção de saberes e sentidos aos quais devemos nos referenciar. Negligenciamos o lugar de compositores de um mundo, este a ser constantemente escrito e inventado, nos paralisando e nos orientando somente a partir da experiência que temos enquanto sujeitos, negligenciando criações que fujam a um universo naturalizado. $\mathrm{O}$ risco da perda destas referências autoimpostas, nas quais se figura a imagem de um "eu mesmo", é o medo da desagregação de si através de novas imagens de mundo. Atitude que põe em xeque a potência de ação no campo social, ou mesmo desencadeia ações que apenas representem o supostamente verossímil da subjetividade dominante. Mas nossa subjetividade é complexa, e não está reduzida a um único tipo de mecanismo de individuação. Há outras possibilidades para se abrir a percepção à multiplicidade 
dos códigos existentes, mesmo que, aparentemente, repetindo e repetindo, dar passagem e escuta aos ínfimos acessos do que possa ser uma diferenciação dos lugares comuns de captura.

Nesse processo, mexemos em placas tectônicas, estratos pesados e antigos podem vir à tona, e, irrompendo na própria linguagem normativa, corpos encontram saídas para a produção de si em outras formas menos convencionais de liberação e assimilação das linhas de forças. Para um corpo que por muito tempo não conheceu ou experimentou o que pode, que não criou escuta para o que existe além das formas, este pode ser um processo disruptivo. Daí a importância de um cuidado clínico que se componha em <au>dência e <pru>dácia, onde a disponibilidade em colocar-se em risco junto com os outros corpos que compõem um dispositivo é fundamental. Manifestações incalculáveis podem ocorrer em uma experimentação como esta, que longe de ser qualquer coisa, é, antes de tudo, pura vida que pulsa.

Esta pesquisa ao problematizar a concepção essencialista que está inserida na produção de subjetividade, com seus modelos estruturantes e normativos do funcionamento subjetivo, quer potencializar as formas relacionais de produção de saberes, incorporando novos processos à vida social, vitalizando relações entre as forças emergentes, dos quais somos agentes. Experienciandonos como moléculas instituintes na busca de aberturas por onde nossa produção de sentidos para a vida não esteja atrelada somente às práticas reprodutoras de verdades fechadas em si mesmas, autoritárias e hierárquicas. Mas que possam também aceitar sua condição de experimentação, processo e erro, para que se tornem insurretas de nossa condição dominada e colonizada. O modo como percebemos e apreendemos a maquinaria entre corpos, que é a maquinaria da vida e da existência, é singular para cada ser vivente e coletivo de seres, o que nos distingue em nossos modos de vida. Esta variação contínua da constituição de mundos é também interdependente dos saberes que legitimamos e afirmamos ao longo de nossa existência individual e coletiva, entrelaçada à cartografia cultural de uma época. Esta cartografia cultural é distribuída em função de saberes e poderes, e de seus interesses. Preponderância que concebe sentidos para a existência, modos de vínculos, constituem as subjetividades e nos dividem enquanto indivíduos - o que no momento nos desiguala em classes sociais, tons de pele, níveis de saúde ou saberes adquiridos.

A constituição de uma ética na produção de si como prática micropolítica requer trabalho cotidiano e produção de rachaduras no grande modelo das relações instituídas. Uma reinvenção sempre inacabada que poliniza o corpo social, ramificando o contágio de uma bússola ética.

Como, então, compor a atividade desejante para que ela esteja atuando para a vida, muito além da sobrevivência? Pergunta para rachar o campo da adaptabilidade compassiva. Como refazer a conjugação dos extratos aos quais nos submetemos, criando saídas para uma vida onde os corpos se enlacem à signos, tons, palavras, escolhendo e aferindo seus pontos de maior potência? Tomemos a bússola ética de Oswald de Andrade: "A alegria é a prova dos nove", o que pode constituir uma sorte de viajante.

Se hoje o que empreendemos como valor para nossos corpos e ações está fadado a ações para a conquista de uma gorda saúde, que se baseia em um tempo cronometrado e disciplina unívoca para o sucesso, como poderemos encontrar nossas experiências comuns de precariedade? Nosso ponto de terceiro mundo que nos leve a encontros menos ensimesmados, fazendo-nos enxergar e perceber o que há de vital em nossas presenças. Por onde produzirmos pensamentos de afeto e delicadeza em nossas relações tão impregnadas de imediatismo? Como dar atenção ao que há em nós que difira da impaciência e da indiferença do que parece impróprio aos nossos corpos privados? Nesse sentido, encontrei uma importância inusitada no que foi experimentado nos encontros dessa viagem ao Norte do país.

É desejável compor-se transductivamente com as forças disponíveis na caosmose terrestre, valendo-se de singular implicação na produção de si e da experimentação da alteridade em nós, como produção de uma ética da existência individual e coletiva. Que passa também 
pela aceitação da condição de vulnerabilidade e efemeridade de nossos corpos, extrapola a vida individualizada, não sucumbe à experiência de finitude em si, tornando-se, assim, uma espécie de solidariedade desobediente, imprescindível à existência do comum. Cumplicidade extramoral, simples e complexa, fundamental ao encontro de forças nômades que liberem a vida de seus lugares de aprisionamento, potência clandestina e micropolítica de nossas clínicas.

Por isso, a criação de territórios de trocas, experimentações e encontros são uma medida ética e política na busca de uma reterritorialização relativamente suave, para o tanto que nós latinoamericanos possamos estar perdidos.

\section{Referências}

DELEUZE, Gilles. Foucault. São Paulo: Brasiliense, 2005.

DELEUZE, Gilles; GUATTARI, Félix. Mil platôs: capitalismo e esquizofrenia, vol. 3. São Paulo: Ed. 34, 1997a.

DELEUZE, Gilles; GUATTARI, Félix. Mil platôs: capitalismo e esquizofrenia, vol. 4. São Paulo: Ed. 34, 1997b. 